05

\title{
Анализ зависимости предела прочности от температуры сверхвысокочастотного нагрева нагруженных гетерогенных материалов (скальных пород) на основе образования роста микротрещин
}

\author{
() М.Г. Менжулин, ${ }^{1}$ Х.Ф. Махмудов ${ }^{2}$ \\ 1 „Горный университет“, \\ 199106 Санкт-Петербург, Россия \\ ${ }^{2}$ Физико-технический институт им. А.Ф. Иоффе РАН, \\ 194021 Санкт-Петербург, Россия \\ e-mail: h.machmoudov@mail.ioffe.ru
}

Поступило в Редакцию 15 ноября 2017 г.

В окончательной редакции 25 октября 2018 г.

Принято к публикации 9 ноября 2018 г.

\begin{abstract}
Анализ зависимости предела прочности гранита от температуры СВЧ-нагрева позволяет выделить следующие характерные участки: при низкотемпературном нагреве до $390 \mathrm{~K}$ наблюдается упрочнение; в интервале температур от 390 до $460 \mathrm{~K}$ происходит снижение прочности за счет зарождения, роста и слияния более мелких трещин и перераспределения их к границам зерен с образованием межзерновой микротрещиноватости; в интервале температур от 460 до $550 \mathrm{~K}$ наблюдается значительное снижение прочности, связанное с разделением зерен на блоки с малой областью концентрации трещин в результате их слияния; при температуре выше $593 \mathrm{~K}$ происходит разрушение, раскол образца гранита за счет развития всех видов микротрещин. Разработанная методика определения рациональных параметров воздействия СВЧ-энергией на разупрочнение скальных горных пород в поле стоячих электромагнитных волн позволяет на основании изучения динамики развития наведенной микротрещиноватости обосновать эффективные параметры воздействия СВЧ-энергии на кварцсодержащие горные породы для их разупрочнения и разрушения.
\end{abstract}

DOI: 10.21883/JTF.2019.05.47465.2563

\section{Введение}

Известен способ разрушения гетерогенного материала (горных пород) в результате СВЧ-воздействия [1-23]. СВЧ-электромагнитное излучение (нагрев) проникает в кварцсодержащую горную породу на достаточно большие глубины, испытывая частичное поглощение по мере воздействия [24-27]. Гранит состоит из набора различных по химическому составу основных минералов: кварц, полевой шпат, слюда, которые ведут себя по разному по отношению к СВЧ-нагреву. Каждая из минеральных компонент обладает своими индивидуальными электрическими свойствами, которые обусловливают поглощение. Даже при относительно невысоких температурах напряжения у границ отдельных минералов могут превысить [28-38] макроскопические пределы прочности минералов и могут возникнуть растягивающие напряжения, приводящие к разрушению $[39,40]$. Причиной этого является неравномерное расширение кварца по различным кристаллографическим направлениям.

\section{Методика измерений}

Определение прочности скальной породы при СВЧнагреве выполнялось с помощью установки частотой $2375 \mathrm{MHz}$ с выходной мощностью $2.0 \mathrm{~kW}$ (рис. 1).
Отметим интересные конструктивные особенности установки, приведенной на рис. 1. СВЧ-энергия от генератора разветвляется на две равные части и подается с обоих концов цепочки типа связанных резонаторов (диафрагмированного волновода) навстречу друг другу через коаксиально-волноводные переходы. В этом случае получается более „мягкий“ нагрев породы, с противоположной стороны размещается экран так, чтобы вектор напряженности электрического поля был направлен перпендикулярно к его поверхности. СВЧ-нагревом образца $\left(S=45 \mathrm{~W} / \mathrm{cm}^{2}\right)$ обеспечивалась плотность тепловых источников $q=2.5 \mathrm{~W} / \mathrm{cm}^{2}$. Объектом исследования явились характерные типы гранитов Ленинградской области: гранит с размером зерен от 0.4 до $4.5 \mathrm{~mm}$ и содержанием минералов в его составе: кварц - 30\%, калиевый полевой шпат - 50\%, плагиоклаз - 10\% и биотит - $10 \%$. Образец гранита в виде бруска сечением $90 \times 45 \mathrm{~mm}$ длиной $200 \mathrm{~mm}$ помещался в волноводный тракт. Одна из сторон образца шлифовалась микропорошками К3-10, М-20, а затем полировалась порошками окиси хрома до получения равномерной зеркальной поверхности. В процессе нагружения регистратор (прибор АСК-3106 (Р-52/2)) вычерчивает диаграмму сжатия. Предел прочности породы определяют по формуле

$$
\sigma_{\text {compr }}=P / F_{0}
$$

где $P$ - нагрузка, соответствующая разрушению, $F_{0}-$ площадь сечения образца. Для оценки прочности скаль- 


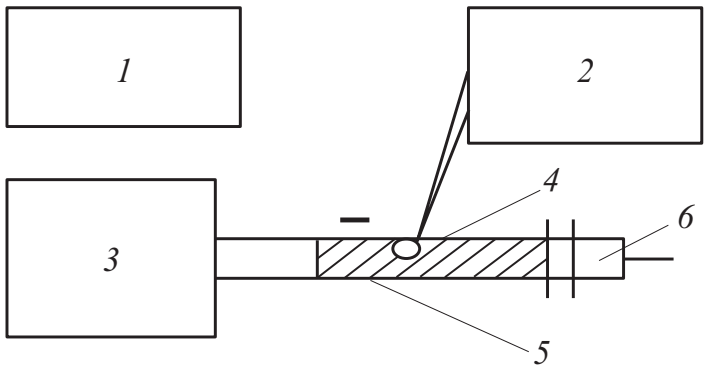

Рис. 1. Блок-схема стенда СВЧ-нагрева: 1 - панорамный измеритель АСК-3106 (Р-52/2), 2 - измеритель напряжения Щ68002-01, 3 - СВЧ-генератор $P=2.0 \mathrm{~kW}, F=2375 \mathrm{MHz}$, 4 - термопара (FLUKE 561), 5 - образец, 6 - поршень.

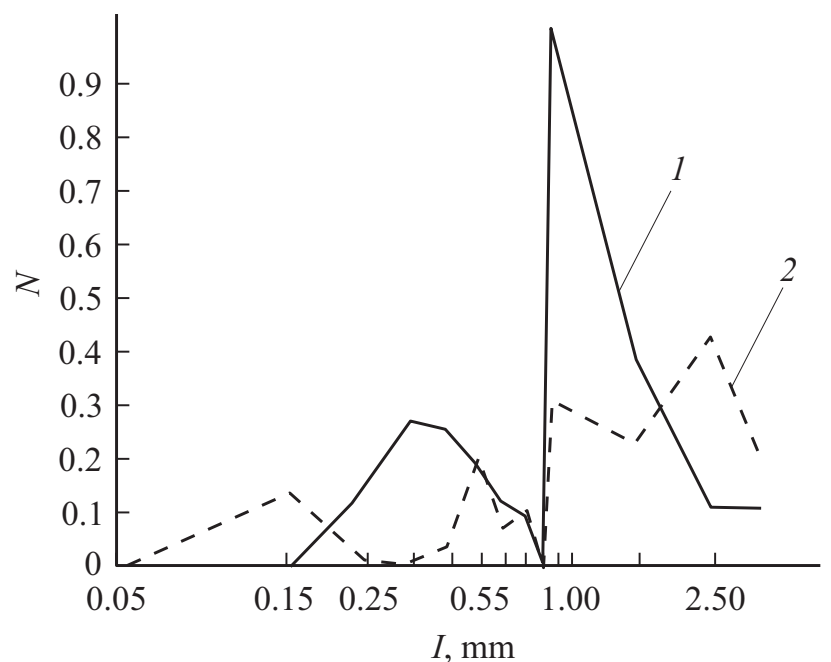

Рис. 2. Распределение $N$ трещин по длине до нагружения (1) и при СВЧ-нагреве (2). $1-n_{239 \mathrm{~K}}=235$ (при $239 \mathrm{~K}$ ), $2-$ $n_{433 \mathrm{~K}}=474$ (при $433 \mathrm{~K}$ ).

ных пород известен способ определения длительной прочности материала [40]. Этот способ относится к анализу материалов путем определения их физических свойств, к определению механического состояния нагруженных материалов, их долговечности и может использоваться для определения времени до возникновения предразрывного состояния в результате накопления трещин в материале [41,42].

При нагружении скальной породы происходит накопление мелких трещин до их некоторой критической концентрации $N=n_{v}$; в единице объема, после чего начинается их попарное слияние с образованием укрупненных трещин. Предельная концентрация трещин длина $l_{i}$ в единице объема $N=1 / K^{3} l_{i}^{3}$, где $K-$ концентрационный параметр слияния трещин, т.е. отношение двух таких длин трещин $l_{2}$ и $l_{1}$, при которых концентрация трещин наибольшая.

Параметры $l_{2}$ и $l_{1}$ находят из графиков распределения трещин для данной температуры СВЧ-нагрева (рис. 2).

Определение распределения концентрации трещин $n_{0}$ и $n_{1}$ по размерам $l_{0}$ и $l_{1}$ осуществлялось с помощью микроскопа „Мир-2“.
Для определения кинетики развития трещин при СВЧ-нагреве предварительно определялась естественная трещиноватость образца $n_{293 \mathrm{~K}}=235$ (при $293 \mathrm{~K}$ ) в единице объема в заданной точке (рис. 2, кривая 1). Для сравнения вероятностей нахождения трещин, соответствующих двум интервалам измерений $\Delta i_{1}$ и $\Delta i_{2}$, удобнее находить плотности вероятностей $f=\left(\Delta n_{i}\right) /\left(\Delta i_{1,2} n_{\Sigma}\right.$ и по величине $F=f l_{i}^{2}$ определять, трещины какой длины вносят основной вклад в разрушение $[27,28,36]$.

После СВЧ-нагружения образца в течении времени $t$ осуществлялось измерение температуры $T$ образца гранита в той же заданной точке в единице объема с помощью термопары, вводимой в щель волноводного тракта, прорезанной по широкой стенке волновода. Установка нагрева включала никель-хром-никелевую термопару, подсоединенную к измерителю температуры Fluke 586 (рис. 1).

Затем под микроскопом определялась в заданной точке и единице объема качественная структура дефектов $n_{433 \mathrm{~K}}=474$ (при $433 \mathrm{~K}$ ) (рис. 2, кривая 2), межзерновая трещиноватость, формирование субблоков, развитие макротрещин и развитие трещин по зерну.

После измерений распределения концентраций трещин $n_{1}$, по размерам $l_{1}$, при различных температурах СВЧ-нагрева (рис. 2, кривая 2) рассчитывались концентрационный параметр слияния трещин $K=l_{2} / l_{1}$ и предельная концентрация трещин длиной $l_{i}$ в единице объема. На основании выполненных в работах $[3,6]$ исследований наведенной трещиноватости, структуры трещин и прочности породы выделены основные стадии электромагнитного разупрочнения (см. таблицу).

На основании графиков распределения концентраций наведенных микротрещин при СВЧ-нагреве определены концентрационный параметр слияния трещин $K(T)$ и критическая концентрация разрушения $N(T)$. Также на

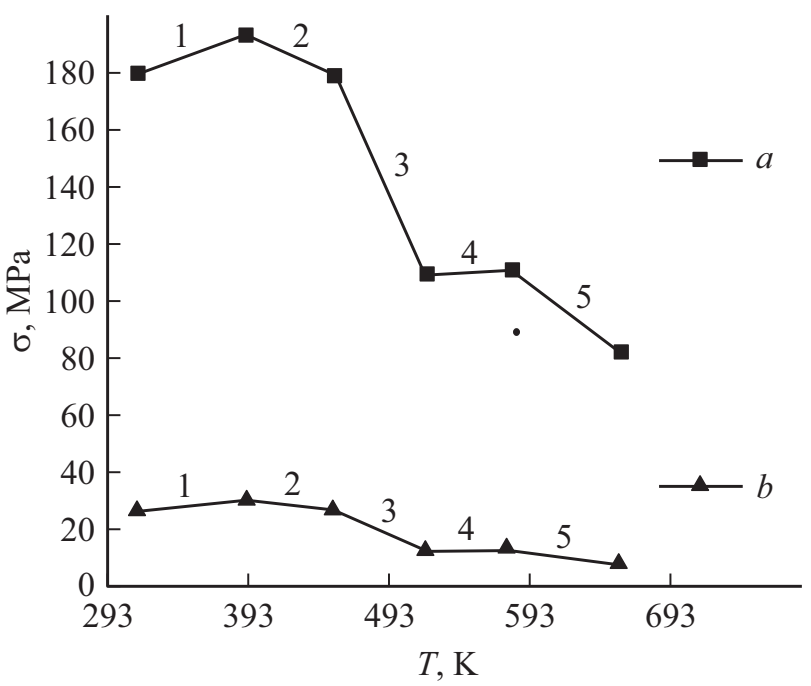

Рис. 3. Зависимости пределов прочности гранита от температуры; $a-$ предел прочности на сжатие, $b-$ предел прочности на растяжение. 
Стадии разупрочнения гранита при СВЧ-нагреве

\begin{tabular}{c|c|c|c|c|c|c}
\hline № & $T$, & $\begin{array}{c}t, \\
\mathrm{~min}\end{array}$ & $\begin{array}{c}\sigma_{\text {comp }}, \\
\text { МРa }\end{array}$ & $\begin{array}{c}\sigma_{\text {stretch }}, \\
\text { МРa }\end{array}$ & $\begin{array}{c}\text { Структура дефектов } \\
\text { (трещин) }\end{array}$ & Технология \\
\hline 1 & $293-390$ & 2 & 195 & 30 & Частичное закрытие & Сушка \\
2 & $390-460$ & $2-4$ & $195-110$ & $26-12$ & Межзерновые трещины & Дезинтеграция \\
3 & $460-550$ & $4-6$ & $110-112$ & $12-12.4$ & Формирования субблоков & Дробление \\
4 & $550-593$ & $6-10$ & $112-82$ & $12-7$ & Развития микротрещин & Дробление \\
5 & $593-660$ & $<10$ & $<80$ & $<7$ & Все виды трещин & Измельчение
\end{tabular}

основании расчетов получена температурная зависимость прочности $\sigma(T)$, (рис. 3).

Анализ зависимости предела прочности от температуры СВЧ-нагрева позволяет выделить следующие характерные участки (рис. 3):

- участок 1 - упрочнение гранита при низкотемпературном нагреве до $390 \mathrm{~K}$;

- участок 2 - снижение прочности гранита в интервале температур от 390 до $460 \mathrm{~K}$ за счет зарождения, роста и слияния более мелких трещин и перераспределения их к границам зерен с образованием межзерновой микротрещиноватости;

- участок 3 - значительное снижение прочности гранита в интервале от 460 до $550 \mathrm{~K}$, связанное с разделением зерен на блоки с малой областью концентрации трещин в результате их слияния, формирования субблоков;

- участок 4 - разрушение, раскол образца гранита за счет развития макротрещин в пучностях электрического поля при температуре 550-593 K;

- участок 5 - развитие всех видов микротрещин при $593-660 \mathrm{~K}$.

Для выделения чистых фракций минералов при селективной дезинтеграции рекомендуется вести обработку при температуре $390-460 \mathrm{~K}$, тогда изменение напряженного состояния способствует образованию межзерновой трещиноватости, что вызывает разупрочнение зерен кварца по их границам и повышает селективность их раскрытия. Экспериментально установлено, что при обработке гранита в режиме первой стадии разделение на чистые фракции размером $1.4 \mathrm{~mm}$ составило 98\%. При механическом дроблении чистота минеральных фракций достигает 80\% только для фракции размером $0.1 \mathrm{~mm}$ [6].

\section{Обсуждения результатов}

Как отмечалось выше, гранит состоит из набора различных по химическому составу основных минералов, обладающих своими электрическими свойствами, обусловливающими поглощение. С другой стороны, могут быть введены и некоторые усредненные диэлектрические параметры среды (для гранита $\varepsilon=5, \operatorname{tg} \delta=0.015-0.018$ на частоте $2.4 \mathrm{GHz}$ ). В начальный момент времени воздействия СВЧ-энергии на породу, когда теплопроводность еще не успевает проявиться, наблюдается существенная неоднородность температуры нагрева минера- лов, входящих в состав данной породы. Кроме того, благодаря разнице в температурах и коэффициентах термического расширения наблюдаются существенно различные по параметрам микронапряжения, что усугубляется наличием структурной неоднородности и естественной микротрещиноватости, приводящих к появлению концентраций напряжений. Наиболее четко эффективность теплового воздействия проявляется вследствие полиморфного превращения $\alpha$-кварца в $\beta$-кварц в интервале температур $573-575 \mathrm{~K}$ и сопровождается мгновенным увеличением объема на $0.86 \%[2,25,43,44]$. Эффективность применения электромагнитного излучения для разупрочнения крепких горных пород может быть достаточно убедительно обоснована на основе сопоставления процессов развития микротрещиноватости при двух типах нагрева, конвекционном и СВЧ [3,6,31]. Для гранитов характерны следующие категории структуры минералов с порогом их насыщения дефектоемкостью:

- минералы с жесткой структурой и с низким порогом дефектоемкости (26\% кварца);

- минералы с подвижной структурой, высокой растворимостью дефектов и высоким порогом насыщения дефектоемкости (5\% слюда);

- минералы с переменной структурой, состоящие как из жестких структурных элементов, так и из подвижных связующих, поэтому значение дефектоемкости и ход насыщения в таких структурах имеют монотоннодискретный характер (36\% полевые шпаты).

Характер разупрочнения и разрушения скальных горных пород определяется температурным режимом, формированием локальных зон нагрева и зон термоупругих напряжение. Эффективность применения СВЧ-энергии определяется способностью породы поглощать электромагнитную энергию. Удельная мощность поглощения

$$
P_{\text {spec }}=2 \pi f \varepsilon^{\prime} \operatorname{tg} \delta|E|^{2},
$$

где $\varepsilon^{\prime}-$ диэлектрическая проницаемость, $\operatorname{tg} \delta$ - тангенс угла диэлектрических потерь, $f$ - частота, $E$ - напряженность электрического поля. В условиях квазиадиабатического нагрева повышение температуры в заданной точке породы определяется выражением $T=P_{s p e c} t / c$, где $t$ - время, $c$ - объемная теплоемкость породы.

Разрушение нагруженных твердых тел является термоактивированным процессом [34-38,45], причем время ожидания разрушения при напряжении $\sigma$ и абсолютной 
температуре $T$ описывается формулой С.Н. Журкова [45]:

$$
\tau=\tau_{0} \exp \left(\left(U_{0}-\gamma \sigma\right) / R T\right),
$$

где $\tau-$ время до разрушения, $\tau_{0}-$ период атомных колебаний, $U_{0}$ - энергия активации, $R-$ универсальная газовая постоянная, $T$ - абсолютная температура материала, $\sigma$ - приложенное напряжение, $\gamma$ структурный коэффициент. Однако этот способ не позволяет оценить стадии разупрочнения скальной породы в процессе нагружения с учетом дефектной структуры, так как дальнейшие шаги связаны с исключением из формулы параметра $\gamma$.

Предлагаемый способ определения разупрочнения нагруженных при СВЧ-нагреве скальных горных пород позволяет устранить указанный недостаток и повысить эффективность разупрочнения скальных горных пород при добыче и переработке минерального сырья при оптимальных режимах электромагнитного нагружения и обусловленного им развития микротрещиноватости.

\section{Выводы}

1. В результате температурных исследований выявлен механизм структурного состояния основных минералов кварцсодержащих горных пород (гранитов), на основании которых можно сделать прогнозную оценку снижения прочности и их технологических свойств в результате воздействия СВЧ-поля.

2. Как показали исследования, при нагревании образца до $390 \mathrm{~K}$ в течении $2 \mathrm{~min}$ происходит частичное закрытие микротрещиноватости на 50\% (технология в режиме 1-й стадии, сушка).

3. В процессе экспериментов удалось проследить развитие различных типов микротрещиноватости в граните в зависимости от времени воздействия СВЧ-энергии:

- в режиме 2-й стадии структурных изменений $(493 \mathrm{~K}$, $t=4 \mathrm{~min}$ ) происходит разупрочнение породы в результате развития микротрещин по границам зерен минералов (технология в режиме 2-й стадии, дезинтеграция);

- в режиме 3-й, 4-й стадий структурных изменений $(560 \mathrm{~K}, t=6 \mathrm{~min})$ наблюдаем в структуре гранита образование субблоков, развитие микротрещин (технология в режиме 3-й, 4-й стадий, дробления);

- в режиме 5-й стадии структурных изменений при температуре выше $673 \mathrm{~K}$ происходит разупрочнение и разрушение гранита в результате развития всех видов микротрещиноватости без какого либо внешнего механического напряжения (технология в режиме 5-й стадии, измельчения).

При разделении минерального сырья на уровне минеральных агрегатов с целью последующей отсортировки пустой породы эффективность разупрочнения может быть достигнута в режиме второй стадии, где происходит формирование субблоков. При дроблении породы выбирается режим, соответствующий третьей стадии. Режим четвертой стадии разупрочнения используется в технологическом цикле измельчения. Результаты используются для практических рекомендаций при выборе режимов СВЧ-электромагнитного воздействия и технологической стадии разупрочнения, соответствующих заданной технологии.

В заключении автор выражает благодарность О.И. Казанину за плодотворное обсуждение результатов.

\section{Список литературы}

[1] Основы разупрочнения мерзлых пород СВЧ-полями. Л.: ЛГИ, 1982. С. 28-42.

[2] Sahoo B.K., De S., Carsky M., Meikap B.C. // Ind. Eng. Chem. Res. 2010. Vol. 49. N 6. P. 3015-3021.

[3] Менжулин М.Г., Соколова Н.В., Шишов А.Н., Хоминский B.A. // Горный информационно-аналитический бюллетень (научно-технический журнал). 1999. № 3. C. $164-167$.

[4] Hui Bo Zhang, Yuemin Zhao, Chenyang Zhou, Chenlong Duan, Liang Dong // Energy Fuels. 2015. Vol. 29. N 2. P. $1243-1248$.

[5] Kingman S.S., Snape C.E., Robinson J.P. // Chem. Res. 2007. Vol. 46. N 14. P. 4811-4818.

[6] Менжулин М.Г., Соколова Н.В., Шишов А.Н. // Горный информационно-аналитический бюллетень (научнотехнический журнал). 2000. № 8. С. 229-233.

[7] Lester E., Kingman S., Dodds C., Patrick J. // Fuel. 2006. Vol. 85. P. 2057-2063.

[8] Ruisanchez E., Arenillas A., Juarez-Perez E.J., Menendez J.A. // Fuel. 2012. Vol. 102. P. 65-71.

[9] Menendez J.A., Arenillas A., Fidalgo B., Fernandez Y., Zubizarreta L., Calvo E.G., Bermadez J.M. // Fuel. Proc. Technol. 2010. Vol. 91. P. 1-8.

[10] Menendez J.A., Juarez-Perez E.J., Ruisanchez E., Bermadez J.M., Arenillas A. // Carbon. 2010. Vol. 49. P. 346-349.

[11] Kanilo P.M., Kazantsev V.I., Rasyuk N.I., Schunemann K., Varviv D.M. // Fuel. 2003. Vol. 82. N 2. P. 187-193.

[12] Varviv D.M., Kazantsev V.I., Kanilo P.M., Rasyuk N.I., Schunemann K., Crytsayenko S.V. // Telecommunication and Radio Engineer. 2004. Vol. 61. N 8. P. 650-662.

[13] Hardgrove R.M. // Trans. Am. Soc. Mech. Eng. 1932. Vol. 54. P. 37-46.

[14] Серго Е.Е. Дробление, измельчение и грохочение полезных ископаемых: учебник для вузов. М.: Недра, 1980. $415 \mathrm{c}$.

[15] Austin L.G., Bagga P., Celik M. // Powder Technol. 1981. Vol. 28. P. 235-240.

[16] Kingman S.W., Rowson N.A. // Mineral Engineer. 1998. Vol. 11. N 11. P. 1081-1088.

[17] Delibalta M.S., Toraman O.Y. // Energy Sci. Technol. 2012. Vol. 3. N 2. P. 46-49.

[18] Sahoo B.K., Dea S., Meikap B.C. // Fuel. Proc. Technol. 2011. Vol. 92. P. 1920-1928.

[19] Sahoo B.K., De S., Carsky M., Meikap B.C. // Ind. Eng. Chem. Res. 2010. Vol. 49. P. 3015-3021.

[20] Kingman S. Microwave Pre-Treatment of Coal and Coal Blends to Improve Milling Performance. BCURA Project B76, Final Report-January 2006. 
[21] Диденко А.Н. СВЧ энергетика теория и практика. М.: Наука, 2003.

[22] Samanli S. // Fuel. 2011. Vol. 90. Р. 659-664.

[23] Красновский С.С., Ари Э.И., Друкованный М.Ф. // Известия ДГИ. 1961. Т. 40. С. 124-130.

[24] Красновский С.С., Захаров Ю.Н. Новые возможности высокочастотного контактного способа разрушения горных пород. Тез. докл. Неделя горняка. М.: МГГУ, 1994. С. 193.

[25] Песчанская Н.Н., Синани А.Б. // ФТТ. 2008. Т. 50. Вып. 1. С. 177-181.

[26] Кохушко А.А., Синани А.Б. // ФТТ. 2005. Т. 47. Вып. 5. С. $812-815$.

[27] Ставрогин А.Н. // Записки Горного института. 2004. T. 156. C. 44-46.

[28] Куксенко В.С., Махмудов Х.Ф., Мансуров В.А., Султонов У., Рустамова М.3. // ФТПРПИ. 2009. № 4. С. 55-59.

[29] Куксенко В.С., Махмудов Х.Ф., Ильинов М.Д., Абдурахмонов 3.М. Вестник инженерной школы Дальневосточного федерального ун-та. 2014. № 3 (20). С. 98-108.

[30] Махмудов Х.Ф. // Деформация и разрушение материалов. 2012. № 8. C. 41-45.

[31] Менэуулин М.Г., Шишов А.Н., Серышев С.В. // ВНИМИ. 1995. C. 59-65.

[32] Куксенко В.С., Махмудов Х.Ф., Манжиков Б.Ц. // ФТПРПИ. 2010. Т. 4. С. 29-40.

[33] Махмудов Х.Ф., Менжсулин М.Г., Захарян М.В., Султонов У., Абдурахмонов З.М. // ЖТФ. 2015. Т. 85. Вып. 11. C. $79-85$.

[34] Махмудов Х.Ф. // ЖТФ. 2011. Т. 81. Вып. 1. С. 76-86.

[35] Махмудов Х.Ф., Куксенко В.С. // ФТТ. 2005. Т. 47. Вып. 5. С. 856-859.

[36] Менжулин М.Г., Махмудов Х.Ф., Куксенко В.С., Султонов У. // Вестник Тамбовского ун-та. Сер. Естественные и технические науки. 2013. Т. 18. № 4-2. С. 1667-1668.

[37] Менжулин М.Г., Махмудов Х.Ф., Щербаков И.П. Наука сегодня: теория, практика, инновации. Ростов-на-Дону, 2014. C. $159-187$.

[38] Менжулин М.Г., Махмудов Х.Ф., Щербаков И.П. LAMBERT Academic.

[39] Дмитриев А.П., Гончаров С.А. Термическое и комбинированное разрушение горных пород. М.: Недра, 1978. 303 с.

[40] Пат. РФ № 2167404. Способ определения длительной прочности материала / В.А. Петров, Г.В. Петров. 05.05.1999.

[41] Куксенко В.С., Махмудов Х.Ф. // Геология и геофизика. 2017. T. 58. № 6. С. 915-923.

[42] Менжулин М.Г., Махмудов Х.Ф. // ЖТФ. 2017. Т. 87. Вып. 7. С. $1040-1048$.

[43] Щербаков И.П., Веттегрень В.И., Мамалимов Р.И., Махмудов Х.Ф. // ЖТФ. 2017. Т. 87. Вып. 8. С. 1182-1184.

[44] Щербаков И.П., Веттегрень В.И., Мамалимов Р.И., Махмудов Х.Ф. // ФТТ. 2017. Т. 59. Вып. 3. С. 556-558.

[45] Журков С.Н. // Вестник АН СССР. 1968. № 3. С. 46-52. 